\title{
Standardized Ginkgo Biloba Extract in the Treatment of Vertigo and/or Tinnitus: A Review of the Literature
}

\author{
Bassel Hallak $^{1 *}$, Andreas Schneider², Dominik Güntensperger ${ }^{3}$, Andreas Schapowal ${ }^{4}$ \\ ${ }^{1}$ Department of Otorhinolaryngology, Sion Hospital, Sion, Switzerland \\ ${ }^{2}$ Medical Practice of Otorhinolaryngology, Baden, Switzerland \\ ${ }^{3}$ Schweizerische Tinnitus-Liga, Mastrils, Switzerland \\ ${ }^{4}$ Medical Practice of Otorhinolaryngology, Landquart, Switzerland \\ Email: *bassel2004@hotmail.com
}

How to cite this paper: Hallak, Bassel., Schneider, A., Güntensperger, D. and Schapowal A. (2021) Standardized Ginkgo Biloba Extract in the Treatment of Vertigo and/or Tinnitus: A Review of the Literature. Advances in Aging Research, 10, 31-57. https://doi.org/10.4236/aar.2021.102002

Received: March 23, 2021

Accepted: March 28, 2021

Published: March 31, 2021

Copyright (c) 2021 by author(s) and Scientific Research Publishing Inc. This work is licensed under the Creative Commons Attribution International License (CC BY 4.0)

http://creativecommons.org/licenses/by/4.0/

\begin{abstract}
Standardized Ginkgo biloba extract (GBE) is an established herbal treatment used for a variety of indications, including vertigo and/or tinnitus. The evidence base in human clinical studies for a clear benefit of GBE in vertigo and/or tinnitus is limited and contradictory due to poor reporting as well as variations in study quality and outcome measures used. The aim of this review is to identify and discuss the rationale for using GBE in the treatment of vertigo and/or tinnitus based on the known pleiotropic actions of GBE and the pathophysiology of vertigo and/or tinnitus. The rationale will be substantiated by a review of the literature in order to identify and evaluate clinical trials investigating the efficacy of GBE in individuals with vertigo and/or tinnitus. The review identified randomized controlled trials (RCTs) investigating the effectiveness of GBE in vertigo and/or tinnitus published in PubMed up to $1^{\text {st }}$ January 2020. In total, 17 RCTs were included 8 of the 9 studies investigating tinnitus and/or vertigo/dizziness found improvements, and 6 of 8 included studies investigating solely tinnitus showed positive effects. Based on the known mechanisms of action of GBE as well as evidence from animal models and human clinical trials identified in this review, GBE is a rational alternative treatment that might provide benefits to individuals with vertigo and/or tinnitus. However, further well-defined RCTs in patients with defined pathological entities are necessary to further substantiate the beneficial effects of GBE for vertigo and/or tinnitus.
\end{abstract}

\section{Keywords}

Ginkgo Biloba, Vertigo, Tinnitus, Dizziness 


\section{Introduction}

Maintaining balance and orientation depend on input from the visual and proprioceptive systems, the inner ear, and integration in the brainstem vestibular nuclei and the cerebellum [1]. Dysfunction of any of these systems can cause disorders of balance and the sense of orientation, often leading to complaints of dizziness and/or vertigo [2].

Vertigo is the illusion of rotation, spinning, or swaying in the objects around or in the patients themselves [3]. Acute vertigo symptoms of the peripheral vestibular system are often associated with nausea, vomiting, sweating and pallor [4]. Many people with vertigo and/or dizziness complaints also experience emotional, memory, and self-perception problems, which are especially common in the elderly [2]. Vertigo and/or dizziness is a common complaint, with an estimated 1-year prevalence between $40 \%$ and $50 \%$ in adults [5] [6]. Vertigo can be tentatively classified as either vestibular or non-vestibular in origin. Dysfunction of the vestibular system (vestibular vertigo) accounts for about a quarter of dizziness complaints and has a 1-year prevalence of $5 \%$ and an annual incidence of $1.4 \%$ [7]. Despite the considerable personal and health care burden of dizziness and vertigo symptoms, a large percentage of the underlying disorders remain under diagnosed and, therefore, are probably insufficiently treated [8].

Tinnitus is the perception of sound in the ears or head without any external or internal acoustic stimulation, hence it is considered a symptom rather than a disease per se [9] [10]. If persistent and either intolerable or sufficiently bothersome, tinnitus and/or hearing loss can have a profound impact on quality of life (QoL), causing functional impairment in thought processing, emotions, hearing, sleep, and concentration [11] [12]. Tinnitus is typically classified as either subjective/sensorineural tinnitus, heard only by the affected person, or objective/somatic tinnitus [13]. Another possible distinction is acute versus chronic tinnitus; if persisting longer than a certain amount of time, conventionally between six and twelve months, it is usually regarded as "chronic", reflecting clinical experience that the phantom sound will persist [14]. Moreover, the etiology of tinnitus is often considered idiopathic, as $40 \%$ of patients report "no known events" associated with their tinnitus onset [9]. It is therefore a heterogeneous disorder with regard to its etiology, presenting symptoms, and perceptual characteristics [15]. Like vertigo, tinnitus is also a common problem in the general population, with prevalence estimates range from $4.6 \%$ to $30 \%$ [16]. The prevalence of tinnitus increases with age and the presence of hearing loss [17]. Using the Short Form Health Survey (SF-36), one study assessing QoL in 53 audiology patients reporting tinnitus showed that $43 \%$ also had impaired QoL, a high level of distress or both [18]. A U.S. cross-sectional analysis representative 12-month health survey evaluating 21.4 million American adults with tinnitus, reported that $27 \%$ experienced symptoms for more than 15 years and $36 \%$ had near-constant symptoms [16]. It is estimated that only about $50 \%$ of sufferers will discuss their tinnitus with a physician, and medications are recommended in less than half of these 
cases [16]. Consequently, tinnitus also remains under diagnosed and insufficiently treated [16].

The ancient herbal extract from the leaves of the Chinese Ginkgo biloba tree, which contains about 250 different compounds involved in many different mechanisms, has shown beneficial effects in treatingneurodegenerative diseases like Alzheimer's, cardiovascular diseases, cancer, stress, memory loss, tinnitus, geriatric complaints like vertigo, age-related macular degeneration, and psychiatric disorders like anxiety disorder, adjustment disorder or schizophrenia [19] [20] [21] [22]. Most randomized controlled trials (RCTs) evaluating the effects of Ginkgo biloba to date have used the standardized dry leaf extract (GBE) EGb 761 and the similarly manufactured LI 1370. In accordance with regulatory requirements, the active components of both pharmaceutical-grade products contain $24 \%$ flavonoids, $6 \%$ triterpenes, and both GBEs are purified to contain less than 5 parts per million ginkgolic acids to avoid toxicity [23] [24] [25].

This review consists of two parts. In part one, we discuss the rationale for using GBE for the treatment of vertigo and/or dizziness and tinnitus based on the complex pathophysiology of these disorders as well as the known mechanism of actions of GBE. In part two, we examine the breadth of literature published to reveal the RCTs conducted in relation to the treatment of vertigo and tinnitus with GBE, with the aim of providing insights and guidance for physicians on where to focus their research.

\section{Rationale for the Use of GBE in Vertigo and/or Dizziness and Tinnitus}

\subsection{Pathophysiology of Vertigo and/or Dizziness and Tinnitus}

The major vestibular structures located in the inner ear include three semicircular ducts (lateral, anterior and posterior), and two otolith organs (saccule and utricle) [26]. The neuroepithelium of these peripheral vestibular organs are lined with hair cells that relay sensory impulses to the brainstem and the cerebellum [26]. Specific processingareas in the brainstem, cerebellum, and cerebral cortex integrate the sensory information from the peripheral vestibular organs, visual system, and proprioceptive system to allow for proper balance and orientation of the body in its environment [26]. Clear vision during head movements is maintained via an automated function called the vestibular ocular reflex (VOR) [1]. At the same time, the vestibular system controls posture via the vestibular spinal reflex (VSR) [1]. Vestibular dysfunction, arising from peripheral or central components of the vestibular system, may cause disorders of balance and the sense of orientation, often leading to vertigo and/or dizziness. Vestibular vertigo covers a broad range of specific vestibular disorders. The supraregional specialized outpatient clinic of the German Center for Vertigo and Balance Disorders at the Department of Neurology of München University, Germany diagnosed incidences of vertigo-related complaints in 34,860 patients (1998-2019) in the following percentiles: functional dizziness $17.3 \%$, benign peripheral paroxysmal 
positional vertigo (BPPV) 14.3\%, central vestibular vertigo/dizziness $13.4 \%$, vestibular migraine $12.3 \%$, Menière's disease $10.1 \%$, unilateral vestibulopathy $9.1 \%$, bilateral vestibulopathy $6.7 \%$, vestibular neuritis $8.2 \%$, vestibular paroxysmia $3.2 \%$, psychogenetic dizziness $2.9 \%$, third mobile window syndromes $0.5 \%$, other $8.6 \%$, and vertigo syndromes of unclear origin $4.5 \%$ [27]. Due to vestibular compensation, symptoms of many peripheral vestibular disorders may resolve after approximately 6 to 12 weeks. This compensation process involves a number of different complex mechanisms of the brain stem and cerebellum, as well as cortical and spinal functions [4] [28]. However, symptomatic improvement is not analogous with recovery of vestibular function, and the vestibular functional loss is often irreversible [4].

Tinnitus is a symptom that may be associated with dizziness and/or vertigo [29]. In some cases, it is associated with sensorineural hearing loss as a result of damage to the auditory system (24\% of tinnitus cases occur due to abnormalities within the inner ear and vestibulocochlear nerve, 35\% originate due to abnormalities in the acoustic pathway), although it can also be associated with other factors, such as some head injuries, exposure to certain drugs, nerve damage or blood-flow problems ( $41 \%$ of cases originate within the supratentorial structures of the brain) [30]. The current consensus is that tinnitus is a disorder involving a distributed network of peripheral and central pathways in the nervous system. Though most cases are idiopathic, some tinnitus patients suffer with sensorineural tinnitus that might be caused by pathophysiological changes in either function or activity of the peripheral (i.e., changes in auditory input at the level of the cochlea and auditory nerve) or central auditory nervous systems [13]. Mazurek et al. (2007) showed that intensive noise exposure or ototoxic drugs can be a factor in the development of tinnitus [31]. Indeed, pathologic changes in cochlear neurotransmission, e.g. destruction of the hair cells in the inner ear by noise-induced hearing loss (NIHL) has been identified as one of the most frequent causes of sensorineural tinnitus [13]. While damage to the inner and outer hair cells in the inner ear often recovers after acute noise exposure, auditory nerve fibers to the inner hair cells appear more vulnerable [32]. Newer research also suggests that synapses between hair cells and cochlear neurons may be affected, which could lead to "hidden hearing loss" that is not detectable with standard audiometric methods (e.g. Liberman, M.C.) [33]. Detectable damage to the auditory periphery by itself seems neither sufficient nor required to give rise to chronic tinnitus, indicating extra-auditory modulation of the auditory sensation [15]. In addition, several observations suggest that tinnitus has neural correlates in the brain, regardless of peripheral damage that might trigger it [15] [34]. For example, in many cases, tinnitus persists after the transection of auditory nerve VIII, which destroys cochlear input to the brain [15] [35]. A proposed neurophysiological model hypothesizes that peripheral changes in input (deafferentation) causes plastic changes to occur, resulting in altered patterns of brain activity due to anatomic changes in the connectivity of central nervous system 
(CNS) neurons [36] [37]. Although the precise mechanism is unclear, several models are under discussion. The neurophysiological model postulates that tinnitus is associated with functional changes not only in the auditory cortex but also in non-auditory regions such as the limbic, frontal, and parietal areas [38]. The most recent model by Sedley et al. [39] is based on predictive coding, in which spontaneous activity in the subcortical auditory pathway constitutes a "tinnitus precursor" which is normally ignored as imprecise evidence against the prevailing percept of "silence". Extant models feature as contributory mechanisms acting to increase either the intensity of the precursor or its precision. If precision (i.e., postsynaptic gain) rises sufficiently then tinnitus is perceived. Perpetuation arises through focused attention, which further increases the precision of the precursor, and resetting of the default prediction to expect tinnitus [39].

\subsection{GBE Mechanism of Action}

GBE has been shown to have neuroprotective effects, including improved energy supply by the mitochondria, antioxidative or radical capturing properties, and to improve cerebral perfusion (through reduction in blood viscosity) and glucose utilization [40]. Which mechanisms play the decisive role in the action of GBE in vertigo and vestibular compensation cannot be stated definitively. Depending on the pathogenetic background, both antioxidative properties and activation of cerebral metabolism may be possible as well as vigilance-enhancing and cognitive activation effects [41].

An influence of GBE on the vestibular system and vestibular compensation could be demonstrated in animal experiment models [42]-[47]. Vestibular compensation could be demonstrated morphologically by an increased new formation of synapses in the vestibular nuclei region of treated cats [44] and biochemically as an increase in protein synthesis in the region of the vestibular nuclei [47].

GBE has demonstrated several effects within the CNS that may enhance neuronal plasticity and neurotransmitter levels. For example, GBE effects have been reported, including, among others, protection of neuronal mitochondrial ATP synthesis in the presence of oxidative stress [48] [49], protection against oxidative damage in erythrocyte membranes [50], which consequently lowers blood viscosity and improves blood flow [51] [52] and neuroprotection through antiapoptotic activity [53] [54] [55] [56] [57].

These effects of GBE have been well documented in both animal and human studies, and may treat tinnitus by preventing free-radical damage to the cochlea, or increasing blood flow and ultimately improving the health of the inner ear [58] [59] [60]. GBE provided a statistically significant decrease in behavioral manifestation of tinnitus induced by sodium salicylate toxicity in a rat model [61]. In 9 Mongolian gerbils (Meriones unguiculatus) that displayed behavioral signs of subjective tinnitus, three weeks of daily oral GBE led to improvement in all 9 animals, with 7 of them showing complete relief of tinnitus [62]. After dis- 
continuation of GBE treatment, tinnitus related behavior reappeared in all but one animal while auditory thresholds remained restored [62]. The authors suggested that a global inhibitory mechanism was involved to counteract tinnitus. Tian et al. (2013) showed that GBE prevents cisplatin-induced hearing loss in rats and enhanced the antiatherogenic effects of cisplatin by inhibiting the generation of reactive oxygen species [63]. Tziridis et al. (2014) investigated the effectiveness of prophylactic treatment with GBE for NIHL and development of tinnitus after noise trauma in an animal model. Results suggested that significant neuroplastic effects of GBE had an effect on auditory processing at the peripheral and central level of the auditory pathway as measured with behavioral and electrophysiological approaches [64]. The authors of this study proposed two main effects of GBE: 1) an increase in auditory brainstem activity leading to an increased thalamic input to the primary auditory cortex; and 2) an asymmetric effect on lateral inhibition in the primary auditory cortex [60] [64].

\section{Methods}

\subsection{Identification of Relevant Studies}

Relevant studies were identified by a systematic search in PubMed of the literature up to 1 January 2020. Studies were eligible for inclusion if they met predefined inclusion criteria: 1) employed a study design with no major methodological shortcomings or bias, e.g. RCT; 2) evaluated an identifiable, standardized GBE, the composition of which is adequately described; 3) treatment dosing and duration ( $\geq 12$ weeks) were appropriate for the indication (tinnitus/vertigo); 4) enrollment of patients (inpatients or outpatients) suffering from vertigo of unknown etiology or not otherwise specified, or tinnitus as the primary or concomitant complaint; and 5) publication in English, French, German, Russian, Spanish, or Italian language. We excluded non-RCT designs (including cross-over designs), combination treatments, and non-human studies.

\subsection{Search Strategy}

RCTs of interest were identified by searching the PubMed database (up to 1 January 2020) using the search terms "Ginkgo" and "vertigo" or "tinnitus" in the title/abstract, and by requesting information on randomized controlled trials of any EGb 761 or LI 1370 GBE product on tinnitus or vertigo from a manufacturer. Reference lists of retrieved studies were searched by hand to ensure all potential RCTs were included. Initial screening was based on title and abstract reading. When there was uncertainty whether or not a record was relevant, the full text record was screened.

\section{Results}

\subsection{Characteristics of Included Studies}

Of the 67 citations retrieved, 17 research reports ( 4 for vertigo only, 5 for vertigo/dizziness and tinnitus, and 8 for tinnitus only) were found eligible and are 
included in this review (Figure 1). The two GBEs, EGb 761 and LI 1370, are deemed analogous products, and equivalence can be assumed based on ESCOPMonographs and the same amounts of the active ingredients flavonglycosides and terpenlactones [24] [65].

Characteristics of the included vertigo and/or tinnitus studies are shown in Table 1 . The majority of included tinnitus and/or vertigo (6/9) and tinnitus only studies (5/8) have been published in the past two decades (i.e., since 2000). The 17 articles range by year between 1986 and 2019. The mean age of patients included in all studies is approximately 60 years.

For included vertigo only studies, all 4 studies used subjective visual analogue scales (VAS) orvertigo symptom scale (VSS), and 2 used the Romberg test and other neuro-otologic and balance tests as the main outcome measures. For the 5 included vertigo/dizziness and tinnitus studies, change in 11-point box scales for the rating of presence and severity of dizziness and tinnitus from baseline was used as a secondary outcomes measure.

\subsection{Efficacy of GBE in Vertigo}

A RCT by Sokolova et al. (2014) showed that there was no statistically significant difference in vertigo treatment outcomes between GBE versus betahistine group, though GBE had a better tolerance profile [66].

Cesarani et al. (1998) reported that in the first month of therapy, vertigo and dizziness improved in patients treated with betahistinedihydrochloride and GBE to a similar extent [67]. Differences in side effects reported in a few patients

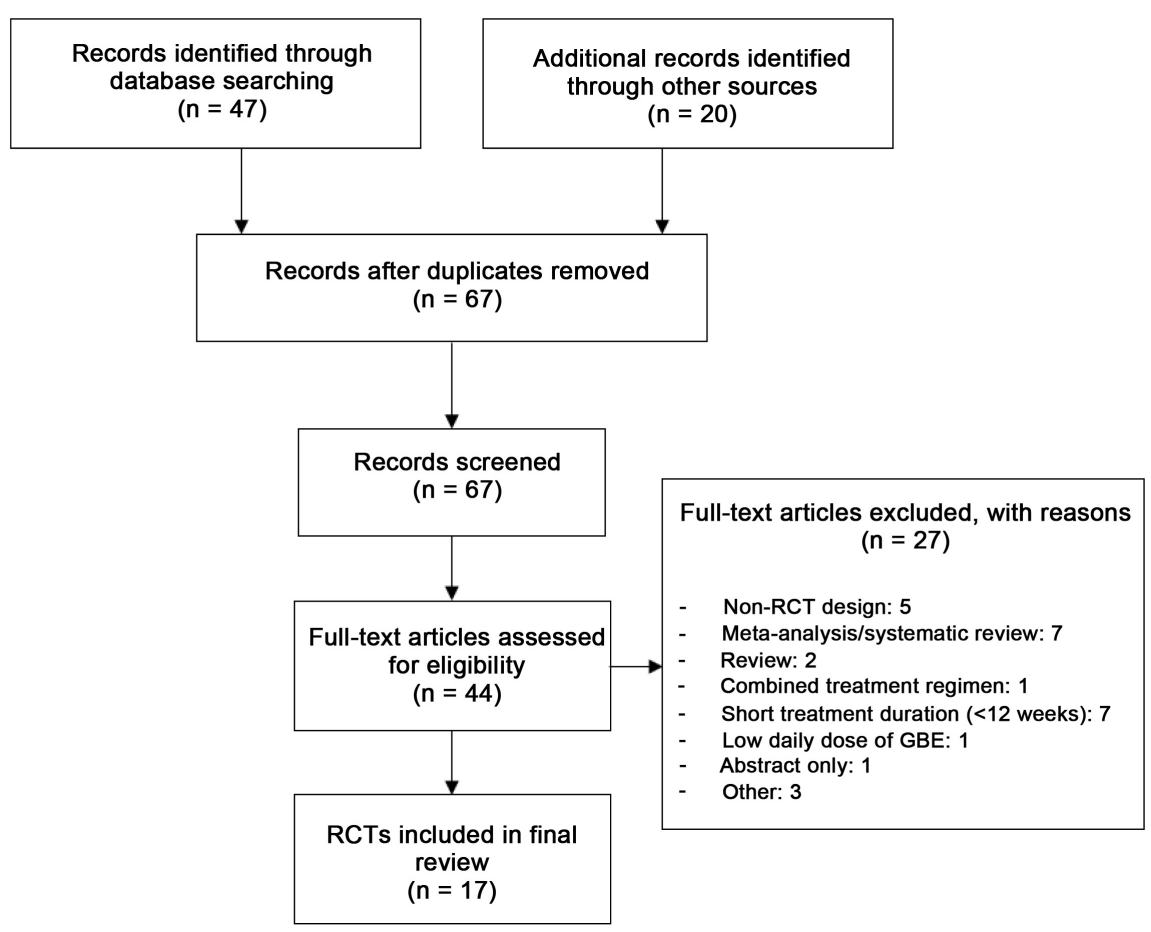

Figure 1. PRISMA flowchart of articles screened for inclusion [114]. RCT: randomized controlled trial; GBE: Ginkgo biloba special extract. 
Table 1. Summary of RCTs for vertigo/dizziness and tinnitus.

\begin{tabular}{|c|c|c|c|c|c|c|c|}
\hline $\begin{array}{c}\text { RCT } \\
\text { (author, year, } \\
\text { reference) }\end{array}$ & $\begin{array}{c}\text { Main } \\
\text { complaint }\end{array}$ & $\begin{array}{c}\text { Study } \\
\text { Design }\end{array}$ & $\begin{array}{c}\text { No. of } \\
\text { patients } \\
\text { randomized }\end{array}$ & $\begin{array}{c}\text { Age of } \\
\text { patients }\end{array}$ & Treatment strategy & $\begin{array}{l}\text { Outcome } \\
\text { measures }\end{array}$ & Key results \\
\hline
\end{tabular}

\begin{tabular}{|c|c|c|c|c|c|c|c|}
\hline $\begin{array}{l}\text { Cesarani, } \\
1998,[67]\end{array}$ & $\begin{array}{l}\text { Vertigo caused by } \\
\text { vascular } \\
\text { vestibular } \\
\text { disorders }\end{array}$ & $\begin{array}{l}\text { Open, } \\
\text { controlled }\end{array}$ & 44 & $\begin{array}{l}47 \text { to } 73 \\
\text { years of age }\end{array}$ & $\begin{array}{l}2 \times 80 \mathrm{mg}=160 \\
\mathrm{mg} \text { EGb } 761 / \text { day } \\
\text { (vs. } 2 \times 16 \mathrm{mg} \\
\text { betahistine) for } 12 \\
\text { weeks, no } \\
\text { information on } \\
\text { follow-up }\end{array}$ & $\begin{array}{l}\text { Change in subjective } \\
\text { symptomatology (VSS), } \\
\text { Romberg test, } \\
\text { Babinsky-Weil test } \\
\text { and other } \\
\text { neuro-otologic and } \\
\text { balance tests. }\end{array}$ & $\begin{array}{l}\text { In the first month of } \\
\text { therapy, vertigo and } \\
\text { dizziness improved in } \\
64.7 \% \text { of patients } \\
\text { treated with betahistine } \\
\text { and in } 65 \% \text { of those } \\
\text { who received GBE. } \\
\text { Considerable } \\
\text { improvement was } \\
\text { found in oculomotor } \\
\text { and visuovestibular } \\
\text { function, although no } \\
\text { change was noted in the } \\
\text { overall balance score. }\end{array}$ \\
\hline $\begin{array}{l}\text { Claussen, } 1985 \\
\text { [article in } \\
\text { German], [69] } \\
\text { [97] }\end{array}$ & $\begin{array}{l}\text { Vertigo and ataxia } \\
\text { symptoms }\end{array}$ & $\begin{array}{l}\text { Randomized, } \\
\text { placebo- } \\
\text { controlled, } \\
\text { double-blind }\end{array}$ & 33 & $\begin{array}{l}\text { Mean: } 59 \\
\text { years }\end{array}$ & $\begin{array}{l}120 \text { mg EGb 761/ } \\
\text { day (vs. placebo) } \\
\text { for } 12 \text { weeks, no } \\
\text { information on } \\
\text { follow-up }\end{array}$ & $\begin{array}{l}\text { Change in } \\
\text { subjective } \\
\text { symptomatology (VSS), } \\
\text { cranio-corpography. }\end{array}$ & $\begin{array}{l}\text { Body sway amplitudes } \\
\text { decreased significantly } \\
\text { more in the GBE } \\
\text { treatment group than } \\
\text { in the placebo group. } \\
\text { There was a } \\
\text { corresponding } \\
\text { improvement in the } \\
\text { vertigo } \\
\text { symptomatology by } \\
20 \% \text { in the placebo } \\
\text { group and by } 50 \% \\
\text { in the GBE } \\
\text { treatment group. }\end{array}$ \\
\hline $\begin{array}{l}\text { Haguenauer, } \\
1986 \text { [article in } \\
\text { French], [68] } \\
\text { [97] }\end{array}$ & $\begin{array}{l}\text { Vertigo } \\
\text { (undetermined } \\
\text { origin) }\end{array}$ & $\begin{array}{l}\text { Randomized, } \\
\text { placebo- } \\
\text { controlled, } \\
\text { double-blind, } \\
\text { multicenter }\end{array}$ & $\begin{array}{l}67 \text { ( } 34 \text { in the } \\
\text { GBE treatment } \\
\text { group and } 33 \\
\text { in the placebo } \\
\text { group) }\end{array}$ & $\begin{array}{l}\text { Mean: } 52 \pm \\
2.5 \text { years for } \\
\text { GBE group } \\
\text { vs. } 46.4 \pm \\
2.4 \text { years for } \\
\text { the placebo } \\
\text { group }\end{array}$ & $\begin{array}{l}160 \text { mg EGb 761/ } \\
\text { day (vs. placebo) } \\
\text { for } 12 \text { weeks, no } \\
\text { information on } \\
\text { follow-up }\end{array}$ & $\begin{array}{l}\text { VAS scale of severity, } \\
\text { Romberg test, } \\
\text { Babinsky-Weil test and } \\
\text { other neuro-otologic } \\
\text { and balance tests } \\
\text { including } \\
\text { electronystagmography. }\end{array}$ & $\begin{array}{l}\text { Statistically significant } \\
\text { improvement in the } \\
\text { intensity, frequency and } \\
\text { duration of vertigo in } \\
\text { the GBE treatment } \\
\text { group. At the end of the } \\
\text { trial, } 47 \% \text { of patients } \\
\text { treated with GBE were } \\
\text { cured of their vertigo } \\
\text { compared to } 18 \% \text { for } \\
\text { those treated with } \\
\text { placebo. }\end{array}$ \\
\hline $\begin{array}{l}\text { Sokolova, } \\
2014,[66]\end{array}$ & $\begin{array}{l}\text { Vertigo } \\
\text { (undetermined } \\
\text { origin) }\end{array}$ & $\begin{array}{l}\text { Randomized, } \\
\text { placebo- } \\
\text { controlled, } \\
\text { double-blind, } \\
\text { multicenterl }\end{array}$ & $\begin{array}{l}160 \text { ( } 80 \text { in the } \\
\text { GBE treatment } \\
\text { group and } 80 \\
\text { in the } \\
\text { betahistine } \\
\text { group) }\end{array}$ & $\begin{array}{l}\text { Mean: } 58 \\
\text { years }\end{array}$ & $\begin{array}{l}240 \mathrm{mg} \text { EGb } 761 / \\
\text { day (vs. } 32 \mathrm{mg} \\
\text { betahistine) for } 12 \\
\text { weeks, } 2 \text { days } \\
\text { follow-up to } \\
\text { monitor adverse } \\
\text { events }\end{array}$ & $\begin{array}{l}\text { NAS, VSS-SF, SDS } \\
\text { and CGI }\end{array}$ & $\begin{array}{l}\text { Both treatment } \\
\text { groups improved } \\
\text { in all outcome } \\
\text { measures-there was } \\
\text { no significant } \\
\text { intergroup difference } \\
\text { with regard to changes } \\
\text { in any outcome } \\
\text { measure. Numerically, } \\
\text { improvements of } \\
\text { patients receiving } \\
\text { GBE were slightly } \\
\text { more pronounced } \\
\text { on all scales. }\end{array}$ \\
\hline
\end{tabular}




\section{Continued}

Mild to

moderate

Herrschaft, dementia

2012, [21] [95] associated with

neuropsychiatric

symptoms
Multicenter,

double-blind,

randomized

placebo-

controlled
Mild to moderate

Ihl, 2011, [21] dementia with

[93] neuropsychiatric symptoms
402 (200 in the

treatment group and 202 in the placebo group)
$>50$ years (no upper limit; mean $65 \pm 9)$

(1)

404 (202 in the treatment $>50$ years group and 202 (no upper in the placebo limit) group); i.d.
Multicenter, randomized, placebocontrolled
240 mg EGb 761/

day (vs. placebo)

for 24 weeks, no

follow-up
Secondary outcome variable: change in 11-point box scales for $\quad$ [95\% CI: $-0.90,-0.26]$ )

the rating of presence Tinnitus: Change from and severity of dizziness baseline at week 24 for and tinnitus from the tinnitus 11-point baseline. placebo was statistically meaningful $(-0.58$ box scale was not
Dizziness: Change from baseline at week 24 for the dizziness

11-point box scale was significant between groups ( -0.6 for GBE vs. -0.2 for placebo; $\mathrm{p}<0.001)$; mean reduction difference in dizziness severity in favor of GBE treated patients compared to significantly different between groups $(-0.4$ for GBE vs. -0.3 for placebo; $\mathrm{p}=0.31$ ); mean reduction difference in tinnitus severity in favor of GBE treated patients compared to placebo was statistically meaningful $(-0.14$ [95\% CI: $-0.50,-0.22]$ ).

Dizziness: Change from baseline at week 24 for the dizziness 11-point box scale was -0.8 for the GBE group and -0.3 for the placebo group; $\mathrm{p}<$ 0.001 ; mean reduction difference in dizziness severity in favor of GBE treated patients

Secondary outcome compared to placebo 240 mg EGb 761/ variable: change in was statistically day (vs. placebo) for 24 weeks, no information on follow-up 11-point box scales for the rating of presence and severity of dizziness Tinnitus: Change from and tinnitus from baseline at week 24 for baseline.

the tinnitus 11-point box scale was -0.5 for the GBE group and -0.1 for the placebo group; $\mathrm{p}<0.001$; mean reduction difference in tinnitus severity in favor of GBE treated patients compared to placebo was statistically meaningful $(-0.97$ [95\% CI: $-1.27,-0.67])$. 


\section{Continued}

Mild to moderate

Napryeyenko, dementia with 2007, [21] [91] neuropsychiatric features
Multicenter, randomized placebocontrolled
Nikolova,

2013, [21] [92] Mild to moderate [article in dementia Russian] $\geq 50$ years (no upper

limit); mean

$395\left(198 \mathrm{GBE} \quad \begin{array}{l}\text { age }=65 \pm 8 \\ 2 \times 120 \mathrm{mg}=240\end{array}\right.$ treatment years for group and $197 \mathrm{GBE}$ placebo treatment group); i.d. group and $63 \pm 8$ years for placebo group mg EGb 761/day (vs. placebo) for 22 weeks, no information on follow-up
Randomized, placebocontrolled, double-blind
Secondary outcome variable: change in patient self-ratings of presence and severity of dizziness and tinnitus using 11-point box scales.

Dizziness: Change

from baseline at week 22 for the dizziness 11-point box scale was -1.7 for the GBE group and -0.3 for the placebo group; $\mathrm{p}<$ 0.001; mean

reduction

difference in dizziness severity in favor of GBE treated patients compared to placebo was statistically meaningful $(-1.93$ [95\% CI: -2.24 , -1.62])

Tinnitus: Change from baseline at week 22 for the tinnitus 11-point box scale was -1.1 for the GBE group and -0.0 for the placebo group; $\mathrm{p}<$ 0.001; mean reduction difference in tinnitus severity in favor of GBE treated patients compared to placebo was statistically meaningful (-1.96 [95\% CI: $-2.35,-1.57])$

Dizziness: Mean reduction difference in tinnitus severity in favor of GBE treated patients compared to placebo was Secondary outcomes 240 mg EGb 761/

$408(203$ received $\mathrm{GBE}$ treatment and 205 received placebo); i.d. day (vs. placebo) for 22 weeks, no information on follow-up variable: change in

11-point box scales for the rating of presence and severity of dizziness and tinnitus from baseline. statistically meaningful $(-0.29$

[95\% CI: -0.88 ,

$-0.30]$ )

Tinnitus: Mean reduction difference in tinnitus severity in favor of GBE treated patients compared to placebo was statistically meaningful $(-0.66$ [95\% CI: $-1.23,-0.09])$. 


\section{Continued}

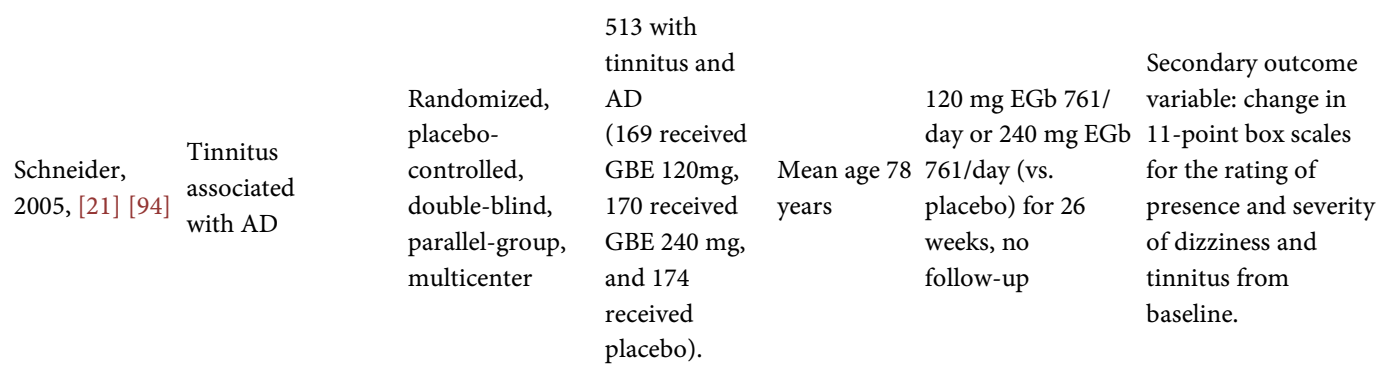

Drew and

Davies, 2001, Tinnitus [77]

Halama, 1988

[71]

[article in

Light to moderate

German] cerebrovascular insufficiency

Randomized double-blind, placebocontrolled
1,121 (559 to

Double-blind, active

placebo-

controlled

treatment

and 562 to

placebo)
Mean: 53

years

$3 \times 50 \mathrm{mg}=150$ mg LI 1370/day (vs. placebo) for 12 weeks, 2 weeks follow-up
$3 \times 40 \mathrm{mg}=120$ mg EGb 761/day

(vs. placebo) for 12 Change in SCAG weeks, no information on follow-up

from baseline.
Mean age

treatment $4 \mathrm{ml}$ containing group $160 \mathrm{mg} \mathrm{EGb}$ 50.97 years $761 /$ day (vs.

vs. placebo placebo) for 12 group 49.76 years weeks, no

follow-up
Dizziness: Mean

reduction difference in dizziness severity in favor of placebo treated patients compared to GBE treated patients (+0.47 [95\% CI: -1.18 , $+2.12]$ )

Tinnitus: Mean reduction difference in tinnitus severity in favor of GBE treated patients compared to placebo was statistically meaningful $(-1.84$ [95\% CI: $-3.00,-0.68])$.

Participants' assessment of tinnitus before, during, and after treatment recorded in a questionnaire (changes in loudness were rated on a 6-point scale and changes in how troublesome were rated on a 5-point scale).

No significant differences between the groups.

[76]
[article in
French]

Multicenter, double-blind, placebocontrolled
103 with

tinnitus
Overall effects were assessed using a 6-point ordinal scale and the symptoms a 4-point ordinal scale.
In the treatment group, SCAG score decreased by an average of 9 points, but remained unchanged in the placebo group ( $\mathrm{p}<0.005$ ); superior effects of GBE were demonstrated for headache and tinnitus.

Better efficacy for GBE vs. placebo irrespective of initial description or prognostic factors; $\mathrm{p}=$ 0.05: a statistically significant difference in favor of the group treated with GBE, the evolution of which was much faster (unilateral test $\mathrm{p}=0.03$ ); duration until disappearance or significant improvement in $50 \%$ of patients was 70 days in the GBE group and 119 days in the placebo group; change in intensity appeared to be statistically better in the GBE group (unilateral test $\mathrm{p}=0.03$ ); and change in nuisance (unilateral test $\mathrm{p}=0.08$ ). 


\section{Continued}

\begin{tabular}{|c|c|c|c|c|c|c|c|}
\hline $\begin{array}{l}\text { Morgenstern, } \\
\text { 1997, [75] } \\
\text { [article in } \\
\text { German] }\end{array}$ & $\begin{array}{l}\text { Non-auditory } \\
\text { tinnitus }\end{array}$ & $\begin{array}{l}\text { Prospective, } \\
\text { double-blind, } \\
\text { randomized, } \\
\text { placebo- } \\
\text { controlled }\end{array}$ & $\begin{array}{l}99 \text { with } \\
\text { tinnitus } \\
\text { ( } 49 \text { in the } \\
\text { treatment } \\
\text { group and } 50 \\
\text { in the placebo } \\
\text { group) }\end{array}$ & $\begin{array}{l}>18 \text { years } \\
\text { (no upper } \\
\text { limit) }\end{array}$ & $\begin{array}{l}3 \times 40 \mathrm{mg}=120 \\
\mathrm{mg} \text { EGb } 761 / \text { day } \\
\text { (vs. placebo) for } 12 \\
\text { weeks, no } \\
\text { follow-up }\end{array}$ & $\begin{array}{l}\text { Audiometrically } \\
\text { detectable change in } \\
\text { tinnitus sound intensity } \\
\text { on the ear that is } \\
\text { initially severely } \\
\text { affected. } \\
\text { Accompanying } \\
\text { variables: } \\
\text { tinnitus-volume } \\
\text { in the contralateral } \\
\text { ear, reproducibility } \\
\text { click-evoked OAE and } \\
\text { their response, tinnitus } \\
\text { intensity, hearing loss } \\
\text { and subjective patient } \\
\text { impression. }\end{array}$ & $\begin{array}{l}\text { From the eighth week } \\
\text { of treatment onwards, } \\
\text { there was a significant } \\
\text { decrease in the average } \\
\text { noise level in the GBE } \\
\text { treatment group. The } \\
\text { observed improvements } \\
\text { were within a range of } 5 \\
\text { to } 10 \text { decibels (dB), } \\
\text { which is considered } \\
\text { clinically relevant; the } \\
\text { values in the placebo } \\
\text { group remained } \\
\text { unchanged. }\end{array}$ \\
\hline $\begin{array}{l}\text { Morgenstern } \\
\text { and } \\
\text { Biermann, } \\
2002,[72]\end{array}$ & $\begin{array}{l}\text { Non-auditory } \\
\text { tinnitus }\end{array}$ & $\begin{array}{l}\text { Double-blind, } \\
\text { randomized, } \\
\text { placebo- } \\
\text { controlled, } \\
\text { monocentric }\end{array}$ & $\begin{array}{l}52 \text { with } \\
\text { tinnitus }\end{array}$ & $\begin{array}{l}\text { median age: } \\
45 \text { years in } \\
\text { the GBE } \\
\text { treatment } \\
\text { group and } \\
47 \text { years in } \\
\text { the placebo } \\
\text { group }\end{array}$ & $\begin{array}{l}2 \times 80 \mathrm{mg}=160 \mathrm{mg} \\
\text { EGb } 761 / \text { day (vs. } \\
\text { placebo) for } 12 \\
\text { weeks, no } \\
\text { information on } \\
\text { follow-up }\end{array}$ & $\begin{array}{l}\text { Primary outcome: } \\
\text { difference in tinnitus } \\
\text { volume between day } 10 \\
\text { of an in-patient phase } \\
\text { and months } 3,2 \text { and } 1 \\
\text { of an out-patient phase, } \\
\text { i.e., change in tinnitus } \\
\text { volume in the more } \\
\text { severely affected ear; } \\
\text { Secondary outcomes: } \\
\text { click-evoked OTE, tone } \\
\text { threshold audiometry, } \\
\text { speech audiometry, } \\
\text { 6-point rating scale of } \\
\text { subjective tinnitus } \\
\text { intensity. }\end{array}$ & $\begin{array}{l}\text { Statistically significant } \\
\text { superiority of GBE over } \\
\text { placebo in the } \\
\text { reduction of the } \\
\text { loudness of subjective } \\
\text { ear sounds (tinnitus) } \\
\text { already evident after } 4 \\
\text { weeks and persisted } \\
\text { until the end of the } \\
\text { study at } 12 \text { weeks } \\
(\mathrm{p}=0.039) \text {. }\end{array}$ \\
\hline $\begin{array}{l}\text { Polanski, 2016, } \\
\text { [78] }\end{array}$ & $\begin{array}{l}\text { Tinnitus } \\
\text { associated with } \\
\text { SSHL }\end{array}$ & $\begin{array}{l}\text { Prospective, } \\
\text { randomized, } \\
\text { double-blinded, } \\
\text { placebo- } \\
\text { controlled }\end{array}$ & $\begin{array}{l}53 \text { with } \\
\text { tinnitus } \\
(12 \mathrm{GBE} \\
\text { treatment } \\
\text { group, } 13 \\
\text { placebo, } 13 \\
\alpha \text {-lipoic acid } \\
\text { plus vitamin } \\
\mathrm{C}, 15 \\
\text { papaverine } \\
\text { hydrochloride } \\
\text { plus vitamin E }\end{array}$ & $\begin{array}{l}\text { Mean age } \\
72.6 \text { years }\end{array}$ & $\begin{array}{l}120 \mathrm{mg} \text { EGb 761/ } \\
\text { day (vs. } \alpha \text {-lipoic } \\
\text { acid [ } 60 \mathrm{mg} / \text { day] } \\
\text { plus vitamin C [600 } \\
\text { mg/day], } \\
\text { papaverine } \\
\text { hydrochloride [100 } \\
\text { mg/day] plus } \\
\text { vitamin E [ } 400 \\
\text { mg/day], and } \\
\text { placebo [starch } \\
\text { capsules] for } 24 \\
\text { weeks, no } \\
\text { information on } \\
\text { follow-up }\end{array}$ & $\begin{array}{l}\text { Change from baseline } \\
\text { in THI. }\end{array}$ & $\begin{array}{l}\text { No statistically } \\
\text { significant difference } \\
\text { between THI by degree } \\
(\mathrm{p}=0.441) \text { and by } \\
\text { score }(\mathrm{p}=0.848) \text { before } \\
\text { and after treatment for } \\
\text { any of the treatment } \\
\text { arms. }\end{array}$ \\
\hline $\begin{array}{l}\text { Procházková, } \\
\text { 2018, [73] }\end{array}$ & $\begin{array}{l}\text { Unilateral or } \\
\text { bilateral chronic or } \\
\text { subchronic tinnitus }\end{array}$ & $\begin{array}{l}\text { Randomized, } \\
\text { double-blind, } \\
\text { reference- } \\
\text { controlled } \\
\text { single-center }\end{array}$ & $\begin{array}{l}200 \text { with } \\
\text { tinnitus (100 } \\
\text { received GBE } \\
\text { treatment and } \\
100 \text { received } \\
\text { pentoxifylline) }\end{array}$ & $\begin{array}{l}\text { Mean age }= \\
55.4 \pm 10.5 \\
\text { years for } \\
\text { GBE treat- } \\
\text { ment group } \\
\text { and } 53.1 \pm \\
10.9 \text { years } \\
\text { for pentox- } \\
\text { ifylline }\end{array}$ & $\begin{array}{l}120 \text { mg EGb 761/ } \\
\text { day (vs. } 600 \mathrm{mg} \\
\text { pentoxifylline/ } \\
\text { day) for } 12 \text { weeks, } \\
\text { no } \\
\text { follow-up }\end{array}$ & $\begin{array}{l}\text { Change in two 11-Point } \\
\text { Box Scales for tinnitus } \\
\text { loudness and } \\
\text { annoyance by tinnitus } \\
\text { from baseline. }\end{array}$ & $\begin{array}{l}\text { Significant } \\
\text { improvements were } \\
\text { observed in the } \\
11 \text {-Point Box Scales for } \\
\text { tinnitus loudness and } \\
\text { annoyance, but there } \\
\text { was no relevant } \\
\text { difference between the } \\
\text { two treatment groups } \\
\text { ( } p=0.93 \text { and } 0.94 \text {, } \\
\text { respectively). }\end{array}$ \\
\hline
\end{tabular}




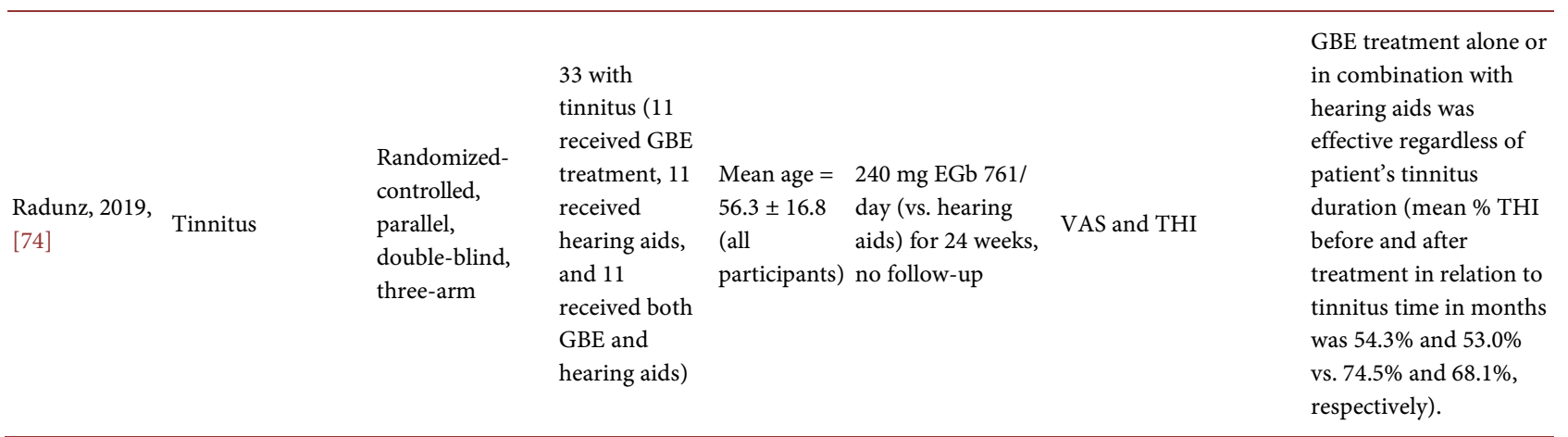

All articles are published in English language unless otherwise stated. GBE: standardized Ginkgo biloba extract LI 1370 orEGb 761 ; i.d.: incomplete data on the number of tinnitus patients at baseline; VAS: Visual Analogue Scales; THI: Tinnitus Handicap Inventory; ADL: activities-of-daily-living; ADL-IS: ADL international scale; GBS: Gottfries-Bråne-Steen; OAE: otoacoustic emissions; SCAG: Sandoz Clinical Assessment Geriatric; SKT: Short Cognitive Performance Test or Syndrom Kurztest; NPI: Neuropsychiatric Inventory; ADCS-GIC: ADCS Clinical Global Impression of Change; ADCS-CGIS: Alzheimer's Disease Cooperative Study Clinical Global Impression of Change; DEMQOL: health-related quality of life (HRQoL) for people with dementia; AD: Alzheimer's Disease; Db: decibels; NAS: numeric analogue scale (NAS) with 0 indicating the absence of vertigo and 10 representing extremely severe vertigo; VSS-SF: short form of the Vertigo Symptom Scale; SDS: Sheehan Disability Scale; CGI: Clinical Global Impressions scale; SSHL: sudden sensorineural hearing loss.

suggest that betahistinedihydrochloride and GBE exert their effects at different equilibrium receptor sites. Moreover, GBE treatment consistently improved VOR [67]. It is however important to note that this is difficult to assess; also the improvement of this symptom does not necessarily mean that vestibular functions are restored.

In a much earlier study, Haguenauer et al. (1986) using EGb 761, showed that GBE treatment for 12 weeks was significantly superior compared to placebo with regard to the improvement in subjective vertigo symptoms, expressed as a reduction in intensity, frequency and duration of vertigo symptoms, and the associated impairments in daily life [68]. Overall, the difference in improvement between the 2 groups reached $85 \%$ at the end of the study ( $p<0.001$ ) [68]. No results were reported for the Romberg or Babinski-Weil tests, and other neuro-otological findings, e.g., spontaneous nystagmus. However in the caloric test, electronystagmographic findings showed normalization in $80 \%$ of those patients having pathological values on enrolment into the study under treatment with GBE vs. $57 \%$ of those who received placebo [68].

Usingcraniocorpographyto evaluate vestibular function, Claussen and Kirtane (1985) found GBE to have a positive effect on subjective dizziness symptoms and lateral body sway vs. placebo [69].

\subsection{Efficacy of GBE in Vertigo/Dizziness and/or Tinnitus}

In the five included RCTs, although the patients treated with GBE had mild to moderate dementia as their primary complaint, 92\% reported associated neurosensory symptoms such as dizziness and/or tinnitus at baseline. An 11-point box scale was used to assess the presence and severity of tinnitus and dizziness as a secondary outcome measure in all trials. In all 5 trials, there was a mean reduction in tinnitus severity for the GBE treated patients compared to placebo. The 
difference in favor of GBE was statistically meaningful in 4 trials, but not in the trial by Herrschaft et al. (2012). In 4 trials (i.e., Nikolova et al. [2013], Napryeyenko et al. [2007], Herrschaft et al. [2012] and Ihl et al. [2011] but not Schneider et al. [2005]), there was a greater reduction in dizziness for the GBE treated patients. All 5 trials show that 22 to 26 weeks of GBE treatment significantly improves concomitant neurosensory symptoms of tinnitus and dizziness (secondary outcome measures) in patients with dementia.

\subsection{Efficacy of GBE in Tinnitus}

Of the 8 tinnitus studies included in our review, six studies reported positive benefits with GBE. Halama et al. (1988) showed that in the GBE group, a superior effect was shown in the symptom of tinnitus $(p=0.035)$ [70] [71]. A combination of infusion therapy followed by oral administration of GBE appears to be effective and safe in alleviating the symptoms associated with tinnitus aurium (also known as subjective or non-auditory tinnitus) [70] [72]. For the primary outcome measure, Morgenstern and Biermann (2002) reported significant superiority of GBE over placebo in the intent-to-treat (ITT) analysis data set after 4, 8 and 12 weeks of out-patient treatment $(\mathrm{p}<0.05,1$-tailed), although the absolute treatment group difference was moderate [72]. The results were supported by the secondary outcome measures for efficacy (e.g., decreased hearing loss, improved self-assessment of subjective impairment) [72]. During out-patient treatment, there were no adverse events related to GBE treatment [70] [72].

Procházková et al. (2018) showed both GBE and pentoxifylline groups improved over the three months but there was no difference between the two groups [73]. Subgroup analyses were performed based on Hospital Anxiety and Depression Scale (HADS), and for participants with a baseline HADS depression score $\geq 8$ (indicating subclinical or clinical depression), there was a statistically significant improvement in Mini-TQ, loudness, and annoyance after 12 weeks in the GBE treatment group that was not seen in the pentoxifylline group [73]. Of the people in the GBE group who had abnormal HADS scores at baseline (34 in the Ginkgo group, 29 in the pentoxifylline group) fewer remained with clinical anxiety than in the pentoxifylline group after 12 weeks $(n=22, P=0.005$ vs. $n=$ 26, $\mathrm{P}=0.105)$ [73].

Radunz et al. (2019) demonstrated that the use of GBE alone or in combination with a hearing aid was effective regardless of patient's tinnitus duration [74]. The authors concluded that this result may be associated with GBE's mode of action, i.e., free radical scavenger activity, anti-inflammatory activity and enhanced neuronal plasticity that can reduce tissue and neurological damage [74].

Although Morgenstern and Biermann (1997) reported a larger regression of tinnitus loudness in the GBE vs. placebo group, the subjective impression change for the patients was not positively impacted [75].

In the earliest study, Meyer (1986) reported that GBE improved the condition of all the tinnitus patients, irrespective of the prognostic factor [76]. 
Two studies were negative with regard to GBE efficacy in tinnitus. Drew and Davies (2001) concluded that GBE is no more effective than placebo in treating tinnitus [77]. In 12 tinnitus patients treated with GBE, Polanski, et al. (2016) reported that there was no benefit from the use of GBE and other antioxidant agents for tinnitus in their study [78].

\section{Discussion}

In contrast to other Ginkgo biloba leaf preparations, the standardized EGb 761 and LI 1370 are considered pharmaceutically equivalent, are well-defined, and have documented efficacy in improving neurologic functions for a wide array of disorders, including cerebrovascular insufficiency [79], memory impairment in the elderly [80], Alzheimer's disease [81], multi-infarct dementia [82], depression [83], peripheral artery insufficiency/improved microcirculation [84] [85], venous insufficiency [86], and asthma [87] [88]. Other studies suggest GBE has potential efficacy in conditions such as tinnitus [76] and vertigo of undetermined etiology [68]. Standardized GBE as a herbal treatment in vertigo and/or tinnitus therefore deserves careful consideration by physicians because of evidence of the promising aforementioned benefits and well-documented tolerability, as well as the limited or complete lack of efficacy with conventional pharmacological agents for these conditions and the increasing patient demand for CAMs [89]. Moreover, given the high patient burden caused by tinnitus and/or vertigo, any therapy that can even moderately improve symptoms can have a considerable impact on QoL for many sufferers [90].

The aim of this review was to identify RCT evidence pertaining to the use of GBE for individuals with symptoms of vertigo of undetermined etiology and/or tinnitus. Except for the two standardized GBE products EGb 761 and LI 1370, our literature search did not identify any RCT of any other Ginkgo preparations in which the effects on tinnitus or dizziness were evaluated. Due to the underlying pathophysiology of these two symptomatic disorders, clinical trials with GBE are based on a rational treatment approach. Of the 4 studies evaluating GBE in vestibular vertigo [66] [67] [68] [69], all showed positive benefits vs. placebo and/or effects similar to betahistine, however we acknowledge there still remains a lack of strength of the evidence, since the observed improvements are subjective (patients' perception) rather than based on objective tests, and more studies are necessary to establish the efficacy of Ginkgo biloba in this indication. Similarly, in most of the 5 studies evaluating GBE in neurosensory symptoms in patients with dementia, GBE was superior to placebo in alleviating symptoms of tinnitus and vertigo/dizziness [91] [92] [93] [94] [95]. Notably, the exact 5 studies evaluated in this review for tinnitus and/or dizziness were previously identified and included in a meta-analysis reported by Spiegel et al. (2018). Based on the Jarad scale assessment of methodological quality, the authors judged that the 5 studies included in their meta-analyses had a low bias risk [21]. Overall, they showed that GBE was superior to placebo, with weighted mean differences for 
change from baseline, calculated using random effects models, of -1.06 (95\% CI: $-1.77,-0.36)$ for tinnitus $(\mathrm{p}=0.003)$ and $-0.77(95 \% \mathrm{CI}:-1.44,-0.09)$ for dizziness $(\mathrm{p}=0.03)$ [21]. Interestingly, our review of the literature with regard to the effects of GBE in this indication (up to 1 January 2020) also failed to identify any additional RCTs that had been published in the last six years, i.e., since the RCT was published by Nikolova et al. in 2013 [92]. Importantly, the included studies on vertigo/dizziness do not follow a pathophysiologically defined definition of the underlying disorder. The fact that different underlying vestibular pathologies can cause different types of vertigo means that treatment should be differentiated based on etiology, and this warrants further study [92].

Although our review includes 9 RCTs which suggest that GBE has clinical efficacy in vestibular and non-vestibular vertigo, we acknowledge that no definitive conclusions can be drawn based on this small evidence-base due to a lack of standardized research methodology between the trials. Although the results from the included studies support findings from animal studies, namely that GBE improves vestibular compensation [96], no human RCT for vertigo was identified with GBE for inclusion in this review in the past 5 years. However, in this context, the general difficulties of transferring results from animal models to humans should be considered, especially in symptoms with an arguably large subjective component. A 2006 systematic review of the literature by Hamann et al. (2006) included 2 of the 4 included vestibular vertigo studies in our review. Hamann et al. reported that GBE as an additional treatment may lead to further improvement in the capacity for compensation with habituation training [97]. They also concluded that central nervous action of GBE has been demonstrated for non-vestibular vertigo (dizziness), i.e., the correlate of a central nervous dysfunction [97].

As evidenced by evaluating the studies identified in our review, results from 13 RCTs of GBE for treating tinnitus, as either the main or concomitant complaint, have yielded conflicting results. A study of 103 patients with tinnitus reported by Meyer in 1986 [76] was positive with regard to GBE vs. placebo efficacy in tinnitus whereas in a more recent study by Polanski, et al. (2016) [78], albeit using different outcome measures and evaluating only 12 tinnitus patients with GBE, reported no benefit with GBE. We consider the group size of only 12 patients in the Polanski study as far too low for a statistically relevant conclusion. The largest trial evaluating GBE in tinnitus to date $(n=1121)$ also failed to show any benefit of GBE in tinnitus, however this study was criticized in a recent systematic review for not meeting minimal standards of Good Clinical Practice [90]. Also, immediately after publication in 2001, Prof. Ernst criticized in his letter to BMJ's editor that this study was only conducted by post and telephone and that therefore the quality and reliability of the rough data was questionable [98]. A meta-analysis of pooled RCTs by Rejali et al. in 2004 concluded that Ginkgo biloba does not benefit patients with tinnitus, but studies included in this meta-analysis used different Ginkgo products of unknown quality [90] [99]. 
In contrast, a more recent systematic review reported by von Boetticher (2011) described that there is a sufficient evidence-base to recommend GBE as a treatment option in tinnitus [90].

There is no Food and Drug Administration (FDA)-approved indication for tinnitus. Antihistamines (e.g., meclizine and dimenhydinate) are currently approved as prescribed vestibular suppressants for vertigo symptoms by the FDA [100]. The European Medicines Agency (EMA) have recently approved three drugs for the treatment of sudden sensorineural hearing loss (SSHL) symptoms, including tinnitus and/or vertigo: 6-fluoro-9-methyl-9H-pyrido[3,4-b]-indole (2018; AudioCure), pioglitazone hydrochloride (2017) and R-azasetronbesylate (2016). Approval for the metabolic drug trimetazidine was withdrawn by the EMA for these indications in 2012 [101]. Although no GBE is currently endorsed for use in tinnitus and vertigo and/or dizziness by the EMA per se, the EMA recognizes that for many European countries (e.g., Austria, Czech Republic, Denmark, Germany, Poland, Romania, Spain, Slovakiaand Switzerland), GBE for tinnitus and vertigo, among other indications, is a well-established treatment [24].

Although vertigo and/or dizziness and tinnitus are common symptoms, there remain few effective therapeutic options available due to the complex and multifaceted neural mechanisms involved in their underlying etiology, and many pharmacotherapies that are available are aimed at ameliorating the QoL impact rather curing the physiological dysfunction [102] [103]. As stated above, no medications have to date been validated or approved for the treatment of tinnitus, and any medical needs are essentially unmet [24]. Typical treatment options for tinnitus include noise masking, pharmaceuticals (tricyclic antidepressants, selective serotonin reuptake inhibitors, pentoxifylline, steroids, etc.), acupuncture, and cognitive behavioral therapy (CBT) [24] [104] [105]. Newer approaches include acoustic stimulation [106] [107] and neuromodulation, such asvagus nerve stimulation [108], transcranic magnetic stimulation, or neurofeedback [109]. Complementary and alternative medicine (CAM) such as herbal supplements, have also stepped into the void created by the lack of consistently effective therapies [89].

Vertigo and tinnitus follow a complex pattern of pathophysiological effects involving an ambiguous interplay between auditory and somatosensory systems, neuro-cognitive, and neuronal-emotional networks [110] [111]. These underlying processes remain poorly understood and require continued investigation. It should be noted in the context of vestibular vertigo that the underlying pathology is not homogenous, and treatment depends on the underlying disease. Betahistidine e.g. is indicated in Menière's disease. Especially in early studies, the underlying pathology of the vestibular vertigo was unknown. This lack of clearly defined underlying pathological entities, especially for studies published before 2000 when diagnostic tools where limited to the lateral semicircular canal function, is a limitation of this review. The two main bioactive constituents of GBE preparations EGb 761 and LI 1370 are flavonoid glycosides (24\%) and terpene 
lactones (6\%); these standardized products also contain less than $5 \mathrm{ppm}$ of the allergenic component, ginkgolic acid [20] [112]. Details of the exact role of neuroplasticity and how exactly the active constituents of GBE act on CNS and cerebral recovery mechanisms considered as key processes in vestibular compensation is as yet not well understood and requires further investigation. Also, tinnitus has recently been shown to be a highly heterogeneous phenomenon that differs greatly between affected individuals. Origin of the percept, subjective manifestation (e.g., intensity, pitch, location), as well as related distress and other comorbid symptoms of tinnitus have thus been found to show considerable variability within the tinnitus group [113], making it highly likely that distinct subtypes of tinnitus may be identified in the future. As the underlying processes of many different tinnitus subtypes are not yet fully understood, the exact mode of action of GBE remains unknown. One of the key advantages of using a herbal medicine such as GBE for treating complex pathophysiological disorders is that it has a pleiotropic mechanism of action and is able to up- or down-regulate different signaling pathways [112].

\section{Conclusion}

GBE is the best-studied phytotherapy medicine to date with excellent tolerability in humans. Based on its known mechanisms of action as well as evidence from animal models and/or human clinical trials, EGb 761 and LI 1370 enable a rational alternative treatment that might provide benefit to individuals with vertigo and/or dizziness and tinnitus. The current consensus is that tinnitus and vertigo disorders involve a distributed network of peripheral and central pathways in the nervous system. Among its many functions, GBE has been shown to reduce vascular resistance, improve peripheral blood circulation and promote neuroprotection, which may positively benefit the pathophysiological changes that occur in patients with tinnitus. Further research into the etiology of vertigo and tinnitus is however important in order to improve our understanding of the pathophysiological mechanisms underlying these symptoms. The heterogeneous nature of tinnitus, in particular, requires more research to determine whether GBE can be of benefit to all patients. Additional trials with standardized research methodologies are also required to further assist physicians in their decision-making for patients with vertigo and/or dizziness and tinnitus symptoms.

\section{Acknowledgements}

Lujain Alkhaldi provided medical writing assistance.

\section{Conflicts of Interest}

The authors state no conflicts of interest.

\section{Funding}

This study was supported by OM Pharma. 


\section{References}

[1] Cullen, K.E. (2012) The Vestibular System: Multimodal Integration and Encoding of Self-Motion for Motor Control. Trends in Neurosciences, 35, 185-196. https://doi.org/10.1016/j.tins.2011.12.001

[2] Borel, L., Lopez, C., Péruch, P. and Lacour, M. (2008) Vestibular Syndrome: A Change in Internal Spatial Representation. Neurophysiologie Clinique, 38, 375-389. https://doi.org/10.1016/j.neucli.2008.09.002

[3] Guerraz, M., Yardley, L., Bertholon, P., Pollak, L., Rudge, P., Gresty, M.A., et al. (2001) Visual Vertigo: Symptom Assessment, Spatial Orientation and Postural Control. Brain, 124, 1646-1656. https://doi.org/10.1093/brain/124.8.1646

[4] Agrup, C., Gleeson, M. and Rudge, P. (2007) The Inner Ear and the Neurologist. Journal of Neurology, Neurosurgery, and Psychiatry, 78, 114-122. https://doi.org/10.1136/jnnp.2006.092064

[5] Bisdorff, A., Bosser, G., Gueguen, R. and Perrin, P. (2013) The Epidemiology of Vertigo, Dizziness, and Unsteadiness and Its Links to Co-Morbidities. Frontiers in Neurology, 4, 29. https://doi.org/10.3389/fneur.2013.00029

[6] Teggi, R., Manfrin, M., Balzanelli, C., Gatti, O., Mura, F., Quaglieri, S., et al. (2016) Point Prevalence of Vertigo and Dizziness in a Sample of 2672 Subjects and Correlation with Headaches. ACTA Otorhinolaryngologica Italica, 36, 215-219. https://doi.org/10.14639/0392-100X-847

[7] Neuhauser, H.K. (2016) The Epidemiology of Dizziness and Vertigo. In: Furman, J.M. and Lempert, T., Eds., Handbook of Clinical Neurology, Vol. 137, Elsevier, Amsterdam, 67-82. https://doi.org/10.1016/B978-0-444-63437-5.00005-4

[8] Neuhauser, H.K., Radtke, A., von Brevern, M., Lezius, F., Feldmann, M. and Lempert, T. (2008) Burden of Dizziness and Vertigo in the Community. Archives of Internal Medicine, 168, 2118-2124. https://doi.org/10.1001/archinte.168.19.2118

[9] Henry, J.A., Dennis, K.C. and Schechter, M.A. (2005) General Review of Tinnitus: Prevalence, Mechanisms, Effects, and Management. Journal of Speech, Language, and Hearing Research, 48, 1204-1235. https://doi.org/10.1044/1092-4388(2005/084)

[10] Jastreboff, P.J. and Hazell, J.W. (1993) A Neurophysiological Approach to Tinnitus: Clinical Implications. British Journal of Audiology, 27, 7-17.

https://doi.org/10.3109/03005369309077884

[11] Nondahl, D.M., Cruickshanks, K.J., Dalton, D.S., Klein, B.E.K., Klein, R., Schubert, C.R., et al. (2007) The Impact of Tinnitus on Quality of Life in Older Adults. Journal of the American Academy of Audiology, 18, 257-266.

https://doi.org/10.3766/jaaa.18.3.7

[12] Zeman, F., Koller, M., Langguth, B. and Landgrebe, M. (2014) Which Tinnitus-Related Aspects Are Relevant for Quality of Life and Depression: Results from a Large International Multicentre Sample. Health and Quality of Life Outcomes, 12, 7. https://doi.org/10.1186/1477-7525-12-7

[13] Chung, J.H. and Lee, S.H. (2016) The Pathophysiologic Mechanism of Tinnitus. Hanyang Medical Reviews, 36, 81-85. https://doi.org/10.7599/hmr.2016.36.2.81

[14] Muller, N., Lorenz, I., Langguth, B. and Weisz, N. (2013) rTMS Induced Tinnitus Relief Is Related to an Increase in Auditory Cortical Alpha Activity. PLoS ONE, 8, e55557. https://doi.org/10.1371/journal.pone.0055557

[15] Adjamian, P., Hall, D.A., Palmer, A.R., Allan, T.W. and Langers, D.R.M. (2014) Neuroanatomical Abnormalities in Chronic Tinnitus in the Human Brain. Neuroscience \& Biobehavioral Reviews, 45, 119-133. 
https://doi.org/10.1016/j.neubiorev.2014.05.013

[16] Bhatt, J.M., Lin, H.W. and Bhattacharyya, N. (2016) Prevalence, Severity, Exposures, and Treatment Patterns of Tinnitus in the United States. JAMA Otolaryngology_Head \& Neck Surgery, 142, 959-965. https://doi.org/10.1001/jamaoto.2016.1700

[17] Coles, R.R. (1984) Epidemiology of Tinnitus: (1) Prevalence. Journal of Laryngology and Otology. Supplement, 9, 7-15. https://doi.org/10.1017/S1755146300090041

[18] Bauch, C.D., Lynn, S.G., Williams, D.E., Mellon, M.W. and Weaver, A.L. (2003) Tinnitus Impact: Three Different Measurement Tools. Journal of the American Academy of Audiology, 14, 181-187. https://doi.org/10.1055/s-0040-1715725

[19] Ramassamy, C., Longpré, F. and Christen, Y. (2007) Ginkgo Biloba Extract (EGb 761) in Alzheimer's Disease: Is There Any Evidence? Current Alzheimer Research, 4, 253-262. https://doi.org/10.2174/156720507781077304

[20] Mahadevan, S. and Park, Y. (2008) Multifaceted Therapeutic Benefits of Ginkgo biloba L.: Chemistry, Efficacy, Safety, and Uses. Journal of Food Science, 73, R14-R19. https://doi.org/10.1111/j.1750-3841.2007.00597.x

[21] Spiegel, R., Kalla, R., Mantokoudis, G., Maire, R., Mueller, H., Hoerr, R., et al. (2018) Ginkgo biloba Extract EGb 761 $\left(^{\circledR}\right)$ Alleviates Neurosensory Symptoms in Patients with Dementia: A Meta-Analysis of Treatment Effects on Tinnitus and Dizziness in Randomized, Placebo-Controlled Trials. Clinical Interventions in Aging, 13, 1121-1127. https://doi.org/10.2147/CIA.S157877

[22] Woelk, H., Arnoldt, K.H., Kieser, M. and Hoerr, R. (2007) Ginkgo biloba Special Extract EGb $761^{\circledast}$ in Generalized Anxiety Disorder and Adjustment Disorder with Anxious Mood: A Randomized, Double-Blind, Placebo-Controlled Trial. Journal of Psychiatric Research, 41, 472-480. https://doi.org/10.1016/j.jpsychires.2006.05.004

[23] Chan, P.-C., Xia, Q. and Fu, P.P. (2007) Ginkgo biloba Leave Extract: Biological, Medicinal, and Toxicological Effects. Journal of Environmental Science and Health, Part C, 25, 211-244. https://doi.org/10.1080/10590500701569414

[24] European Medicines Agency, Committee on Herbal Medicinal Products (HMPC) (2014) Assessment Report on Ginkgo biloba L., Folium.

https://www.ema.europa.eu/en/documents/herbal-report/final-assessment-report-gi $\underline{\text { nkgo-biloba-l-folium_en.pdf }}$

[25] European Medicines Agency (EMA). (2015) Overview of Comments Received on European Union Herbal Monograph on Ginkgo biloba L., Folium 2015.

https://www.ema.europa.eu/en/documents/herbal-comments/final-overview-comm ents-received-european-union-herbal-monograph-ginkgo-biloba-l-folium_en.pdf

[26] Khan, S. and Chang, R. (2013) Anatomy of the Vestibular System: A Review. NeuroRehabilitation, 32, 437-443. https://doi.org/10.3233/NRE-130866

[27] Strupp, M., Dlugaiczyk, J., Ertl-Wagner, B.B., Rujescu, D., Westhofen, M. and Dieterich, M. (2020) Vestibular Disorders. Deutsches Ärzteblatt International, 117, 300-310. https://doi.org/10.3238/arztebl.2020.0300

[28] Strupp, M., Arbusow, V., Maag, K.P., Gall, C. and Brandt, T. (1998) Vestibular Exercises Improve Central Vestibulospinal Compensation after Vestibular Neuritis. Neurology, 51, 838-844. https://doi.org/10.1212/WNL.51.3.838

[29] Pajor, A.M., Ormezowska, E.A. and Jozefowicz-Korczynska, M. (2013) The Impact of Co-Morbid Factors on the Psychological Outcome of Tinnitus Patients. European Archives of Oto-Rhino-Laryngology, 270, 881-888. https://doi.org/10.1007/s00405-012-2079-3 
[30] Swain, S.K., Nayak, S., Ravan, J.R. and Sahu, M.C. (2016) Tinnitus and Its Current Treatment-Still an Enigma in Medicine. Journal of the Formosan Medical Association, 115, 139-144. https://doi.org/10.1016/j.jfma.2015.11.011

[31] Mazurek, B., Stöver, T., Haupt, H., Gross, J. and Szczepek, A. (2007) The Role of Cochlear Neurotransmitters in Tinnitus. HNO, 55, 964-971.

https://doi.org/10.1007/s00106-007-1624-7

[32] Furman, A.C., Kujawa, S.G. and Liberman, M.C. (2013) Noise-Induced Cochlear Neuropathy Is Selective for Fibers with Low Spontaneous Rates. Journal of Neurophysiology, 110, 577-586. https://doi.org/10.1152/jn.00164.2013

[33] Liberman, M.C. (2017) Noise-Induced and Age-Related Hearing Loss: New Perspectives and Potential Therapies. F1000Research, 6, 927.

https://doi.org/10.12688/f1000research.11310.1

[34] Barnea, G., Attias, J., Gold, S. and Shahar, A. (1990) Tinnitus with Normal Hearing Sensitivity: Extended High-Frequency Audiometry and Auditory-Nerve Brain-Stem-Evoked Responses. Audiology, 29, 36-45. https://doi.org/10.3109/00206099009081644

[35] Baguley, D.M., McFerran, D. and Hall, D.A. (2013) Tinnitus. The Lancet (London, England), 382, 1600-1607. https://doi.org/10.1016/S0140-6736(13)60142-7

[36] Jastreboff, P.J. (1990) Phantom Auditory Perception (Tinnitus): Mechanisms of Generation and Perception. Neuroscience Research, 8, 221-254. https://doi.org/10.1016/0168-0102(90)90031-9

[37] Phillips, J.S. and McFerran, D. (2010) Neurophysiological Model-Based Treatments for Tinnitus. Cochrane Database of Systematic Reviews, No. 1, CD008248. https://doi.org/10.1002/14651858.CD008248

[38] De Ridder, D., Elgoyhen, A.B., Romo, R. and Langguth, B. (2011) Phantom Percepts: Tinnitus and Pain as Persisting Aversive Memory Networks. Proceedings of the National Academy of Sciences of the United States of America, 108, 8075-8080. https://doi.org/10.1073/pnas.1018466108

[39] Sedley, W., Friston, K.J., Gander, P.E., Kumar, S. and Griffiths, T.D. (2016) An Integrative Tinnitus Model Based on Sensory Precision. Trends in Neurosciences, 39, 799-812. https://doi.org/10.1016/j.tins.2016.10.004

[40] DeFeudis, F. (1998) Ginkgo biloba Extract (EGb $761^{\circledR}$ ). From Chemistry to the Clinic. Ullstein Medical, Wiesbaden.

[41] Hamann, K.F. (2007) Ginkgo Special Extract EGb $761^{\circledR}$ in Vertigo: A Systematic Review of Randomised, Double-Blind, Placebo-Controlled Clinical Trials. The Internet Journal of Otorhinolaryngology, 7, 1-6. https://doi.org/10.5580/639

[42] Lacour, M., Ez-Zaher, L. and Raymond, J. (1991) Plasticity Mechanisms in Vestibular Compensation in the Cat Are Improved by an Extract of Ginkgo biloba (EGb 761). Pharmacology Biochemistry and Behavior, 40, 367-379. https://doi.org/10.1016/0091-3057(91)90568-M

[43] Maclennan, K., Smith, P.F. and Darlington, C.L. (1995) Ginkgolide B Accelerates Vestibular Compensation of Spontaneous Ocular Nystagmus in Guinea Pig Following Unilateral Labyrinthectomy. Experimental Neurology, 131, 273-278. https://doi.org/10.1016/0014-4886(95)90049-7

[44] Tighilet, B., Leonard, J. and Lacour, M. (1995) Betahistine Dihydrochloride Treatment Facilitates Vestibular Compensation in the Cat. Journal of Vestibular Research, 5, 53-66. https://doi.org/10.1016/0957-4271(94)00023-U

[45] Yabe, T., Chat, M., Malherbe, E. and Vidal, P.P. (1992) Effects of Ginkgo biloba Ex- 
tract (EGb 761) on the Guinea Pig Vestibular System. Pharmacology Biochemistry and Behavior, 42, 595-604.

https://doi.org/10.1016/0091-3057(92)90004-Y

[46] Denise, P. and Bustany, P. (1989) The Effect of Extract of Ginkgo biloba (EGb 761 ${ }^{\oplus}$ ) on Central Compensation of a Total Unilateral Peripheral Vestibular Deficit in the Rat. In: Lacour, M., Toupet, M., Denise, P. and Christen, Y., Eds., Vestibular Compensation: Facts, Theories and Clinical Perspectives, Elsevier, Paris, 201-208.

[47] Bustany, P., Denise, P., Pottier, M. and Moulin, M. (1992) Brain Protein Synthesis after Unilateral Labyrinthectomy: Natural One Month and EGb $761^{\circledR}$ Treatment Effect. In: Christen, Y., Costentin, J. and Lacour, M., Eds., Effects of Ginkgo biloba Extract on the Central Nervous System, Elsevier, Paris, 57-74.

[48] Abdel-Kader, R., Hauptmann, S., Keil, U., Scherping, I., Leuner, K., Eckert, A., et al. (2007) Stabilization of Mitochondrial Function by Ginkgo biloba Extract (EGb 761). Pharmacological Research, 56, 493-502. https://doi.org/10.1016/j.phrs.2007.09.011

[49] Eckert, A., Keil, U., Scherping, I., Hauptmann, S. and Muller, W.E. (2005) Stabilization of Mitochondrial Membrane Potential and Improvement of Neuronal Energy Metabolism by Ginkgo biloba Extract EGb 761. Annals of the New York Academy of Sciences, 1056, 474-485. https://doi.org/10.1196/annals.1352.023

[50] DeFeudis, F.V. and Drieu, K. (2004) "Stress-Alleviating” and "Vigilance-Enhancing" Actions of Ginkgo biloba Extract (EGb 761). Drug Development Research, 62, 1-25. https://doi.org/10.1002/ddr.10351

[51] Wu, Y., Li, S., Cui, W., Zu, X., Du, J. and Wang, F. (2008) Ginkgo biloba Extract Improves Coronary Blood Flow in Healthy Elderly Adults: Role of EndotheliumDependent Vasodilation. Phytomedicine, 15, 164-169.

https://doi.org/10.1016/j.phymed.2007.12.002

[52] Müller, W.E. and Chatterjee, S.S. (2003) Cognitive and Other Behavioral Effects of EGb 761 in Animal Models. Pharmacopsychiatry, 36, S24-S31.

https://doi.org/10.1055/s-2003-40459

[53] Luo, Y., Smith, J.V., Paramasivam, V., Burdick, A., Curry, K.J., Buford, J.P., et al. (2002) Inhibition of Amyloid-Beta Aggregation and Caspase-3 Activation by the Ginkgo biloba Extract EGb761. Proceedings of the National Academy of Sciences of the United States of America, 99, 12197-121202.

https://doi.org/10.1073/pnas.182425199

[54] Massieu, L., Morán, J. and Christen, Y. (2004) Effect of Ginkgo biloba (EGb 761) on Staurosporine-Induced Neuronal Death and Caspase Activity in Cortical Cultured neurons. Brain Research, 1002, 76-85.

https://doi.org/10.1016/j.brainres.2003.12.018

[55] Schindowski, K., Leutner, S., Kressmann, S., Eckert, A. and Müller, W.E. (2001) Age-Related Increase of Oxidative Stress-Induced Apoptosis in Mice Prevention by Ginkgo biloba Extract (EGb761). Journal of Neural Transmission (Vienna), 108, 969-978. https://doi.org/10.1007/s007020170016

[56] Wu, Y., Wu, Z., Butko, P., Christen, Y., Lambert, M.P., Klein, W.L., et al. (2006) Amyloid-Beta-Induced Pathological Behaviors Are Suppressed by Ginkgo biloba Extract EGb 761 and Ginkgolides in Transgenic Caenorhabditis elegans. Journal of Neuroscience, 26, 13102-13113. https://doi.org/10.1523/JNEUROSCI.3448-06.2006

[57] Yang, T.H., Young, Y.H. and Liu, S.H. (2011) EGb 761 (Ginkgo biloba) Protects Cochlear Hair Cells against Ototoxicity Induced by Gentamicin via Reducing Reactive Oxygen Species and Nitric Oxide-Related Apoptosis. Journal of Nutritional Biochemistry, 22, 886-894. https://doi.org/10.1016/j.jnutbio.2010.08.009 
[58] Didier, A., Droy-Lefaix, M.T., Aurousseau, C. and Cazals, Y. (1996) Effects of Ginkgo biloba Extract (EGb 761) on Cochlear Vasculature in the Guinea Pig: Morphometric Measurements and Laser Doppler Flowmetry. European Archives of Oto-Rhino-Laryngology, 253, 25-30. https://doi.org/10.1007/BF00176698

[59] Smith, G.S., Romanelli-Gobbi, M., Gray-Karagrigoriou, E. and Artz, G.J. (2013) Complementary and Integrative Treatments: Tinnitus. Otolaryngologic Clinics of North America, 46, 389-408. https://doi.org/10.1016/j.otc.2013.02.005

[60] Sereda, M., Xia, J., Scutt, P., Hilton, M.P., El Refaie, A. and Hoare, D.J. (2019) Ginkgo biloba for Tinnitus. Cochrane Database of Systematic Reviews, No. 12, CD013514. https://doi.org/10.1002/14651858.CD013514

[61] Jastreboff, P.J., Zhou, S., Jastreboff, M.M., Kwapisz, U. and Gryczynska, U. (1997) Attenuation of Salicylate-Induced Tinnitus by Ginkgo biloba Extract in Rats. Audiology and Neurotology, 2, 197-212. https://doi.org/10.1159/000259244

[62] Krauss, P., Tziridis, K., Buerbank, S., Schilling, A. and Schulze, H. (2016) Therapeutic Value of Ginkgo biloba Extract EGb 761(R) in an Animal Model (Meriones unguiculatus) for Noise Trauma Induced Hearing Loss and Tinnitus. PLoS ONE, 11, e0157574. https://doi.org/10.1371/journal.pone.0157574

[63] Tian, C.J., Kim, Y.J., Kim, S.W., Lim, H.J., Kim, Y.S. and Choung, Y.H. (2013) A Combination of Cilostazol and Ginkgo biloba Extract Protects against Cisplatin-Induced Cochleo-Vestibular Dysfunction by Inhibiting the Mitochondrial Apoptotic and ERK Pathways. Cell Death \& Disease, 4, e509.

https://doi.org/10.1038/cddis.2013.33

[64] Tziridis, K., Korn, S., Ahlf, S. and Schulze, H. (2014) Protective Effects of Ginkgo biloba Extract EGb 761 against Noise Trauma-Induced Hearing Loss and Tinnitus Development. Neural Plasticity, 2014, Article ID: 427298.

https://doi.org/10.1155/2014/427298

[65] (ESCOP) ESCoP (2003) Gingko Folium. ESCOP Monograph: The Scientific Foundation for Herbal Medicinal Products. 2nd Edition, Thieme, Exeter, 178-210.

[66] Sokolova, L., Hoerr, R. and Mishchenko, T. (2014) Treatment of Vertigo: A Randomized, Double-Blind Trial Comparing Efficacy and Safety of Ginkgo biloba Extract EGb 761 and Betahistine. International Journal of Otolaryngology, 2014, Article ID: 682439. https://doi.org/10.1155/2014/682439

[67] Cesarani, A., Meloni, F., Alpini, D., Barozzi, S., Verderio, L. and Boscani, P.F. (1998) Ginkgo biloba (EGb 761) in the Treatment of Equilibrium Disorders. Advances in Therapy, 15, 291-304.

[68] Haguenauer, J.P., Cantenot, F., Koskas, H. and Pierart, H. (1986) Treatment of Equilibrium Disorders with Ginkgo biloba Extract. A Multicenter Double-Blind Drug vs. Placebo Study. La Presse médicale, 15, 1569-1572.

[69] Claussen, C.F. and Kirtane, M.V. (1985) Randomisierte Doppelblindstudie zur Wirkung von Extractum Gingko biloba bei Schwindel und Gangunsicherheit des älteren Menschen. Springer, Berlin. https://doi.org/10.1007/978-3-642-70035-4_4

[70] European Medicines Agency (EMA) (2014) Assessment Report of Ginkgo biloba L., Folium.

https://www.ema.europa.eu/en/documents/herbal-report/draft-assessment-report-g inkgo-biloba-1-folium_en.pdf

[71] Halama, P., Bartsch, G. and Meng, G. (1988) Disorders of Brain Performance of Vascular Origin. Randomized Double-Blind Study of the Effectiveness of Ginkgo biloba Extract. Fortschritte der Medizin, 106, 408-412.

[72] Morgenstern, C. and Biermann, E. (2002) The Efficacy of Ginkgo Special Extract 
EGb 761 in Patients with Tinnitus. International Journal of Clinical Pharmacology and Therapeutics, 40, 188-197. https://doi.org/10.5414/CPP40188

[73] Prochazkova, K., Sejna, I., Skutil, J. and Hahn, A. (2018) Ginkgo biloba Extract EGb 761((R)) versus Pentoxifylline in Chronic Tinnitus: A Randomized, Double-Blind Clinical Trial. International Journal of Clinical Pharmacy, 40, 1335-1341. https://doi.org/10.1007/s11096-018-0654-4

[74] Radunz, C.L., Okuyama, C.E., Branco-Barreiro, F.C.A., Pereira, R.M.S. and Diniz, S.N. (2019) Clinical Randomized Trial Study of Hearing Aids Effectiveness in Association with Ginkgo biloba Extract (EGb 761) on Tinnitus Improvement. Brazilian Journal of Otorhinolaryngology, 86, 734-742. https://doi.org/10.1016/j.bjorl.2019.05.003

[75] Morgenstern, V.C. and Biermann, E. (1997) Long-Term Tinnitus Therapy with Ginkgo Special Extract EGb 761. Fortschritte der Medizin, 115, 57-58. (In German)

[76] Meyer, B. (1986) A Multicentre, Randomized, Double-Blind Drug versus Placebo Study of Ginkgo biloba Extract in the Treatment of Tinnitus. La Presse médicale, 15, 1562-1564. (In French)

[77] Drew, S. and Davies, E. (2001) Effectiveness of Ginkgo biloba in Treating Tinnitus: Double Blind, Placebo Controlled Trial. BMJ (Clinical Research ed), 322, 73. https://doi.org/10.1136/bmj.322.7278.73

[78] Polanski, J.F., Soares, A.D. and de Mendonça Cruz, O.L. (2016) Antioxidant Therapy in the Elderly with Tinnitus. Brazilian Journal of Otorhinolaryngology, 82, 269-274. https://doi.org/10.1016/j.bjorl.2015.04.016

[79] Kleijnen, J. and Knipschild, P. (1992) Ginkgo biloba for Cerebral Insufficiency. British Journal of Clinical Pharmacology, 34, 352-358. https://doi.org/10.1111/j.1365-2125.1992.tb05642.x

[80] Rai, G.S., Shovlin, C. and Wesnes, K.A. (1991) A Double-Blind, Placebo Controlled Study of Ginkgo biloba Extract ("Tanakan") in Elderly Outpatients with Mild to Moderate Memory Impairment. Current Medical Research and Opinion, 12, 350-355. https://doi.org/10.1185/03007999109111504

[81] Janssen, I.M., Sturtz, S., Skipka, G., Zentner, A., Velasco Garrido, M. and Busse, R. (2010) Ginkgo biloba in Alzheimer's Disease: A Systematic Review. Wiener Medizinische Wochenschrift, 160, 539-546. https://doi.org/10.1007/s10354-010-0844-8

[82] Kanowski, S., Herrmann, W.M., Stephan, K., Wierich, W. and Hörr, R. (1996) Proof of Efficacy of the Ginkgo biloba Special Extract EGb 761 in Outpatients Suffering from Mild to Moderate Primary Degenerative Dementia of the Alzheimer Type or Multi-Infarct Dementia. Pharmacopsychiatry, 29, 47-56. https://doi.org/10.1055/s-2007-979544

[83] Dai, C.-X., Hu, C.-C., Shang, Y.-S. and Xie, J. (2018) Role of Ginkgo biloba Extract as an Adjunctive Treatment of Elderly Patients with Depression and on the Expression of Serum S100B. Medicine (Baltimore), 97, e12421-e. https://doi.org/10.1097/MD.0000000000012421

[84] Schneider, B. (1992) Ginkgo biloba Extract in Peripheral Arterial Diseases. Meta-Analysis of Controlled Clinical Studies. Arzneimittelforschung, 42, 428-436.

[85] Jung, F., Mrowietz, C., Kiesewetter, H. and Wenzel, E. (1990) Effect of Ginkgo biloba on Fluidity of Blood and Peripheral Microcirculation in Volunteers. Arzneimittelforschung, 40, 589-593.

[86] Janssens, D., Michiels, C., Guillaume, G., Cuisinier, B., Louagie, Y. and Remacle, J. 
(1999) Increase in Circulating Endothelial Cells in Patients with Primary Chronic Venous Insufficiency: Protective Effect of Ginkor Fort in a Randomized Double-Blind, Placebo-Controlled Clinical Trial. Journal of Cardiovascular Pharmacology, 33, 7-11. https://doi.org/10.1097/00005344-199901000-00002

[87] Tang, Y., Xu, Y., Xiong, S., Ni, W., Chen, S., Gao, B., et al. (2007) The Effect of Ginkgo biloba Extract on the Expression of PKCa in the Inflammatory Cells and the Level of IL-5 in Induced Sputum of Asthmatic Patients. Journal of Huazhong University of Science and Technology, 27, 375-380.

https://doi.org/10.1007/s11596-007-0407-4

[88] Li, M.H., Zhang, H.L. and Yang, B.Y. (1997) Effects of Ginkgo Leave Concentrated Oral Liquor in Treating Asthma. Chinese Journal of Integrated Traditional and Western Medicine, 17, 216-218.

[89] European Parliament (2017) Complementary and Alternative Therapies for Patients Today and Tomorrow.

https://www.europarl.europa.eu/cmsdata/135562/ENVI\%202017-10\%20WS\%20CA M\%20\%20PE\%20614.180\%20(Publication).pdf

[90] von Boetticher, A. (2011) Ginkgo biloba Extract in the Treatment of Tinnitus: A Systematic Review. Neuropsychiatry Disease and Treatment, 7, 441-447.

https://doi.org/10.2147/NDT.S22793

[91] Napryeyenko, O. and Borzenko, I. (2007) Ginkgo biloba Special Extract in Dementia with Neuropsychiatric Features. A Randomised, Placebo-Controlled, Double-Blind Clinical Trial. Arzneimittelforschung, 57, 4-11. https://doi.org/10.1055/s-0031-1296579

[92] Nikolova, G., Yancheva, S., Raychev, I. and Hoerr, R. (2013) PLAGIN Study Group Ginkgo biloba Extract in Dementia: A 22-Week Randomised, Placebo-Controlled, Double-Blind Trial. Bulgarian Neurology, 14, 139-143.

[93] Ihl, R., Bachinskaya, N., Korczyn, A.D., Vakhapova, V., Tribanek, M., Hoerr, R., et al. (2011) Efficacy and Safety of a Once-Daily Formulation of Ginkgo biloba Extract EGb 761 in Dementia with Neuropsychiatric Features: A Randomized Controlled Trial. International Journal of Geriatric Psychiatry, 26, 1186-1194. https://doi.org/10.1002/gps.2662

[94] Schneider, L.S., DeKosky, S.T., Farlow, M.R., Tariot, P.N., Hoerr, R. and Kieser, M. (2005) A Randomized, Double-Blind, Placebo-Controlled Trial of Two Doses of Ginkgo biloba Extract in Dementia of the Alzheimer's Type. Current Alzheimer Research, 2, 541-551. https://doi.org/10.2174/156720505774932287

[95] Herrschaft, H., Nacu, A., Likhachev, S., Sholomov, I., Hoerr, R. and Schlaefke, S. (2012) Ginkgo biloba Extract EGb 761 $\left(^{\star}\right)$ in Dementia with Neuropsychiatric Features: A Randomised, Placebo-Controlled Trial to Confirm the Efficacy and Safety of a daily Dose of $240 \mathrm{mg}$. Journal of Psychiatric Research, 46, 716-723. https://doi.org/10.1016/j.jpsychires.2012.03.003

[96] Lindner, M., Gosewisch, A., Eilles, E., Branner, C., Krämer, A., Oos, R., et al. (2019) Ginkgo biloba Extract EGb 761 Improves Vestibular Compensation and Modulates Cerebral Vestibular Networks in the Rat. Frontiers in Neurology, 10, 147. https://doi.org/10.3389/fneur.2019.00147

[97] Hamann, K.F. (2006) Special Ginkgo Extract in Cases of Vertigo: A Systematic Review of Randomised, Double-Blind, Placebo Controlled Clinical Examinations. HNO, 55, 258-263. https://doi.org/10.1007/s00106-006-1440-5

[98] Ernst, E. (2001) Marketing Studies and Scientific Research Must Be Distinct. BMJ (Clinical Research ed), 322, 1249. https://doi.org/10.1136/bmj.322.7296.1249 
[99] Rejali, D., Sivakumar, A. and Balaji, N. (2004) Ginkgo biloba Does Not Benefit Patients with Tinnitus: A Randomized Placebo-Controlled Double-Blind Trial and Meta-Analysis of Randomized Trials. Clinical Otolaryngology and Allied Sciences, 29, 226-231. https://doi.org/10.1111/j.1365-2273.2004.00814.x

[100] Food and Drug Administration (FDA). Vertigo Medications 2000-2020. https://www.drugs.com/search.php?searchterm=VERTIGO

[101] European Medicines Agency (EMA). Trimetazidine 2012. https://www.ema.europa.eu/en/medicines/human/referrals/trimetazidine

[102] McFerran, D.J., Stockdale, D., Holme, R., Large, C.H. and Baguley, D.M. (2019) Why Is There No Cure for Tinnitus? Frontiers in Neuroscience, 13, 802. https://doi.org/10.3389/fnins.2019.00802

[103] Strupp, M. and Brandt, T. (2008) Diagnosis and Treatment of Vertigo and Dizziness. Deutsches Ärzteblatt International, 105, 173-180. https://doi.org/10.3238/arztebl.2008.0173

[104] Cima, R.F.F., Mazurek, B., Haider, H., Kikidis, D., Lapira, A., Noreña, A., et al. (2019) A Multidisciplinary European Guideline for Tinnitus: Diagnostics, Assessment, and Treatment. HNO, 67, 10-42. https://doi.org/10.1007/s00106-019-0633-7

[105] Cima, R.F., Maes, I.H., Joore, M.A., Scheyen, D.J., El Refaie, A., Baguley, D.M., et al. (2012) Specialised Treatment Based on Cognitive Behaviour Therapy versus Usual Care for Tinnitus: A Randomised Controlled Trial. The Lancet, 379, 1951-1959. https://doi.org/10.1016/S0140-6736(12)60469-3

[106] Pantev, C., Wollbrink, A., Roberts, L.E., Engelien, A. and Lutkenhoner, B. (1999) Short-Term Plasticity of the Human Auditory Cortex. Brain Research, 842, 192-199. https://doi.org/10.1016/S0006-8993(99)01835-1

[107] Strauss, D.J., Corona-Strauss, F.I., Seidler, H., Haab, L. and Hannemann, R. (2017) Notched Environmental Sounds: A New Hearing Aid-Supported Tinnitus Treatment Evaluated in 20 Patients. Clinical Otolaryngology, 42, 172-175.

https://doi.org/10.1111/coa.12575

[108] Tyler, R., Cacace, A., Stocking, C., Tarver, B., Engineer, N., Martin, J., et al. (2017) Vagus Nerve Stimulation Paired with Tones for the Treatment of Tinnitus: A Prospective Randomized Double-Blind Controlled Pilot Study in Humans. Scientific Reports, 7, Article No. 11960. https://doi.org/10.1038/s41598-017-12178-w

[109] Guntensperger, D., Thuring, C., Kleinjung, T., Neff, P. and Meyer, M. (2019) Investigating the Efficacy of an Individualized Alpha/Delta Neurofeedback Protocol in the Treatment of Chronic Tinnitus. Neural Plasticity, 2019, Article ID: 3540898. https://doi.org/10.1155/2019/3540898

[110] Cacace, A.T. (2003) Expanding the Biological Basis of Tinnitus: Cross-Modal Origins and the Role of Neuroplasticity. Hearing Research, 175, 112-132. https://doi.org/10.1016/S0378-5955(02)00717-7

[111] Rajagopalan, A., Jinu, K.V., Sailesh, K.S., Mishra, S., Reddy, U.K. and Mukkadan, J.K. (2017) Understanding the Links between Vestibular and Limbic Systems Regulating Emotions. Journal of Natural Science, Biology and Medicine, 8, 11-15. https://doi.org/10.4103/0976-9668.198350

[112] Smith, J.V. and Luo, Y. (2004) Studies on Molecular Mechanisms of Ginkgo biloba Extract. Applied Microbiology and Biotechnology, 64, 465-472. https://doi.org/10.1007/s00253-003-1527-9

[113] Langguth, B., Kreuzer, P.M., Kleinjung, T. and De Ridder, D. (2013) Tinnitus: Causes 
and Clinical Management. The Lancet Neurology, 12, 920-930.

https://doi.org/10.1016/S1474-4422(13)70160-1

[114] Moher, D., Liberati, A., Tetzlaff, J., Altman, D.G. and The, P.G. (2009) Preferred Reporting Items for Systematic Reviews and Meta-Analyses: The PRISMA Statement. PLOS Medicine, 6, e1000097.

https://doi.org/10.1371/journal.pmed.1000097

\section{Abbreviations}

BPPV: Benign Paroxysmal Positional Vertigo;

CAM: Complementary Alternative Medicine;

CBT: Cognitive Behavioral Therapy;

EMA: European Medicines Agency;

ESCOP: European Scientific Cooperative on Phytotherapy;

FDA: Food and Drug Administration;

GBE: Ginkgo Biloba extract;

HADS: Hospital Anxiety and Depression Scale;

Mini-TQ: Mini-Tinnitus Questionnaire;

NIHL: Noise-Induced Hearing Loss;

QoL: Quality of Life;

RCT: Randomized Controlled Trial;

SSHL: Sudden Sensorineural Hearing Loss;

VAS: Visual Analogue Scale;

VOR: Vestibular Ocular Reflex;

VSR: Vestibular Spinal Reflex;

VSS: Vertigo Symptom Scale. 